\title{
An Efficiency-orientated Total Factor Productivity Measurement Model for Construction Projects
}

\author{
Wenting Zhan ${ }^{1 *}$ and Wei Pan ${ }^{2}$ \\ ${ }^{1}$ Ph.D. Candidate, Department of Civil Engineering, The University of Hong Kong \\ ${ }^{2}$ Associate Professor, Department of Civil Engineering, The University of Hong Kong \\ *Corresponding author's e-mail: zhanwt11@connect.hku.hk
}

\begin{abstract}
Modularization and mechanization are widely promoted due to their potential benefits in enhancing site efficiency. However, the outcomes of the implementation lack quantitative supports at the project level. This paper aims to develop a quantitative evidence-based methodology for measuring site efficiency and evaluating the outcomes of the two technologies. Applying the proposed methodology to a real-life building construction project, the simulation results of multiple scenarios show that site efficiency is likely to be enhanced by encouraging the utilisation of laboring-saving materials and equipment within the limited project budget. The findings provide quantitative evidence to encourage technological innovation in construction materials and equipment, thereby demonstrating the potential of substituting materials or equipment for labor in benefiting site efficiency of a construction project through adopting modularization and mechanization.
\end{abstract}

\section{KEYWORDS}

Construction project; Productivity enhancement; Modularization; Mechanization

\section{INTRODUCTION}

Construction productivity has received great attention in the context of construction and engineering management. However, productivity in construction in general has been alleged to be lower than that in many other industrial sectors (Borg and Song 2015). Therefore, the need of productivity enhancement has triggered the rapid emergence of many new construction technologies such as modularization and mechanization (Pan et al. 2019; Yang et al. 2018). Modularization and mechanization are two labor-saving technologies and have been reported with substantial benefits for buildings (Yang et al. 2018). Many studies found that equipment technology has a greater impact on productivity; technological advance in the equipment is characterized by the substitution of equipment for labor in the manufacture of goods (Goodrum and Haas 2004), resulting in production's increase in the equipment-to-labor ratio (Salter 1966). Similarly, if material technology has a greater improvement, it would result in a declining material-to-labor ratio (Goodrum et al. 2009). Recent research found that within the relationship of symbiosis, construction productivity is beneficial by adopting both technologies (Yang et al. 2018). Investigations into the benefits of the two construction technologies prevail at the industry level (Yang et al. 2018), but there is a lack of quantitative evidence to support adopting Site Efficiency Enhancement Strategies (SEESs) concerning modularization and mechanization at the project level. Lacking of quantitative evidence of adopting modularization and mechanization at 
the project level supports the need for development of a simulation tool for SEESs evaluation. In order to evaluate SEESs, a series of hypotheses was proposed:

H1: Site efficiency can be enhanced by adopting modularization

H2: Site efficiency can be enhanced by adopting mechanization

H3: Site efficiency can be enhanced by adopting both modularization and mechanization

Due to the project-based nature of the construction industry (Abdel-Wahab and Vogl 2011), it is essential to better understand how construction productivity is measured at the project level and how construction productivity is enhanced by addressing "achieve more with less" (Mandal and Vong 2016). The concepts "productivity", "efficiency" and "effectiveness" are often used confusedly when conducting a performance evaluation for a project. However, these words represent distinctly different measures (Zhan and Pan 2018). Efficiency means doing things right (Linna et al. 2010) and is conceptualized as how efficiently quantity of input resources are transformed into quantity of outputs (Pritchard 1995). While, effectiveness highlights doing the right things (Linna et al. 2010) and is conceptualized as how well a system uses its resources to achieve its goals (Pritchard 1995). Productivity is a broad concept which includes the subconcepts of efficiency and effectiveness (Jääskeläinen 2010). This paper, therefore, uses the term "site efficiency" to indicate how construction output depends on its tangible and intangible inputs (Vogl and Abdel-Wahab 2015).

A variety of measurement models have emerged in literature, offering opportunities for measuring site efficiency of a construction project. Critiquing these studies reveals two knowledge gaps. One resides with the ignorance of Total Factor Productivity (TFP) approach in modelling. The studies generally addressed labor input (Abdel-Razek et al. 2007; Ellis and Lee 2006; Liao et al. 2012), but few studies embraced material and equipment inputs (Thomas et al. 1990), let alone the consideration for intangible inputs such as regulatory compliance and site management (Javed et al. 2018; Sveikauskas et al. 2016). The considerable impact of these tangible and intangible inputs on site efficiency reinforces their importance in site efficiency measurement (Mirahadi and Zayed 2016; Park 2006). The other gap concerns the pre-assumed linearly homogeneous relationship among construction inputs. By this assumption, the complex relationships among the inputs, e.g., heterogeneous, causes difficulties in using such measurement models. In the wake of these gaps, this paper has considered the application of production function with second-order flexible to model the complex relationships between construction output and various construction inputs (Coelli et al. 2005).

\section{SITE EFFICIENCY MEASUREMENT AND SEESS EVALUATION}

The quantitative evidence-based methodology for measuring site efficiency and evaluating SEESs has consisted of four phases. The first two phases show how the site efficiency is measured and the last two phases reveal the quantitative evidence for informing the outcomes after adopting three SEESs based on simulation results of multiple scenarios.

\section{Phase 1: Development of the CES function-based site efficiency measurement model}

Heterogeneous construction inputs required the production function of the multi-input singleoutput production system to be second-order flexible (Coelli et al. 2005). Quadratic, Translog, Leontief, and Constant-Elasticity-of-Substitution (CES) are the second-order production functions (Coelli et al. 2005). CES function is more flexible (Henningsen and Henningsen 2011). Working with the CES function, the relationship between construction output (i.e., dependent 
variable) and construction inputs (i.e., independent variables) can be modelled by the CES function-based site efficiency measurement model and mathematically expressed as

$$
y=\gamma\left(\sum_{i=1}^{n} \alpha_{i}\left(x_{i}\right)^{-\rho}\right)^{-v / \rho}
$$

where $y$ is the value of construction output; $x=\left(x_{1}, \ldots, x_{i}, \ldots, x_{n}\right)$ are the value of construction inputs; $\gamma$ denotes site efficiency, where $\gamma \in(0,+\infty) ; \alpha_{i}$ denotes the functional distribution of construction input $i$ where $\alpha_{i} \in[0,1]$ and $\sum_{i=1}^{n} \alpha_{i}=1 ; \rho$ is the (constant) elasticity of substitution where $\rho \in[-1,0) \cup(0, \infty)$; and $v$ is the elasticity of scale where $v \in[0, \infty) . \gamma, \alpha_{i}$, $\rho$ and $v$ are parameters to be estimated.

In accordance with the characteristics of CES function, the proposed model is flexible since the structure of the model is determined by the parameters. Specifically speaking, for $\rho \rightarrow 0$, the CES function turns to the Cobb-Douglas form; for $\rho \rightarrow \infty$, the CES function turns to the Leontief production function; and, for $\rho \rightarrow-1$, the CES turns to a linear function, especially, if $v=1$, the CES function turns to the linearly homogeneous form (Thomas et al. 1990). Meanwhile, through applying the proposed model in site efficiency analysis, the model provides a reliable approach to: 1) model the multi-input and single-output production system of construction process; 2) combine heterogeneous sources of data; and, 3) conduct "what-if" analysis to explore the effect of changes in some inputs on the output.

\section{Phase 2: Computation the parameters}

Applying a first-order Taylor series expansion to the logarithmized CES function-based site efficiency model at the point $\rho=0$, we have

$$
\ln y=\ln \gamma+v \sum_{i=1}^{n} \alpha_{i} \ln x_{i}-\frac{\rho v}{2} \sum_{\forall i \in n, i<j}^{n} \sum_{\forall j \in n, i<j}^{n} \alpha_{i} \alpha_{j}\left(\ln x_{i}-\ln x_{j}\right)^{2} .
$$

Consider Eq. (2) above as a multiple linear regression model for $L$ observations and $K$ independent variables. The collinearity problem is the existence of linear relationships between two or more independent variables in Eq. (2). Variance Inflation Factor (VIF) is used as objective methods to detect the existence of collinearity. The rule of thumb cut-off value for VIF is 10. If VIF is less than 10, Ordinary Least Squares (OLS) estimation method is applied. If VIF is greater than 10, the initial values of the parameters are estimated by ridge regression method.

Next, the parameters are optimized by minimizing the sum of squares between the real and the estimated value of construction output (Eq. 3). Quasi-Newton method and Broyden-FletcherGoldfarb-Shanno algorithm are engaged in the optimization process.

$$
\varepsilon=\min \sum_{l=1}^{L}\left(y_{l}-\gamma^{*}\left(\sum_{i=1}^{n} \alpha_{i}^{*}\left(x_{i_{l}}\right)^{-\rho^{*}}\right)^{-v^{*} / \rho^{*}}\right)^{2}
$$

where $\varepsilon$ is the sum of squares between the real and the estimated output; $y_{l}$ is the value of construction output at the $l^{\text {th }}$ observation; $x_{l}=\left(x_{1 l}, \ldots, x_{i_{l}}, \ldots, x_{i_{l}}\right)$ are the value of construction inputs at the $l^{\text {th }}$ observation; $\gamma^{*}, \alpha_{i}{ }^{*}, \rho^{*}$ and $v^{*}$ are optimized value of parameters.

\section{Phase 3: Scenario analysis}

There were four kinds of scenarios developed, assessed and analyzed, namely 1) the baseline model which demonstrates the current status; 2) the controlled model I which shows the improvement after adopting modularization (H1); 3) the controlled model II which shows the 
improvement after adopting mechanization (H 2); and, 4) the controlled model III which implies the condition with the two innovative technologies are implemented simultaneously $(\mathrm{H} 3)$. The SEESs are evaluated based comparison between the results of different scenarios within each model, making

$$
Y^{m}=\max \sum_{l=1}^{L} \gamma^{*}\left(\sum_{i=1}^{n} \alpha_{i}^{*}\left(x^{m}{ }_{i_{l}}\right)^{-\rho^{*}}\right)^{-v^{*} / \rho^{*}},
$$

where $Y^{m}$ is the value of the constructed facility under the model $m$, where $m=1,2,3,4 ; x^{m}{ }_{i_{l}}$ is the value of construction inputs under the model $m$. Through the comparison between the results of different models, SEESs could be evaluated to improve the reliability of construction productivity management.

\section{CASE STUDY}

The proposed CES function-based site efficiency model was contextualized within a real-life building project. The case project adopted cast-in-situ concrete construction method which can represent the status quo of typical residential building design. The case project began on middle 2011 and was completed at the end of 2012, taking 510 calendar days (73 weeks).

In order to ensure the reliability and validity of the findings, triangulated data sources obtained from documentation analysis, site visits, and group interviews were collected and analyzed (Yin 2014). During the site visit, the project team introduced the project background and also provided relevant project documents. A group interview was also undertaken with the representatives of the project team to gain an in-depth understanding of the project. During the group interview, the interviewees were asked to identify the project-specific site efficiencyinfluencing factors within the context of the case project and to assess and quantify the factors based on available resources. The group interview lasted for around one hour. The interviewees included professional and managerial staff members representing various project participants of different project stakeholders, i.e., client (4), contractor (3), consultant (1) and supplier (1), who directly and indirectly participated in construction activities. Multiple documents have been collected and adopted for data analysis. Archival records of the project, including drawings, site dairies, progress reports and financial reports, etc. were provided by the project stakeholders for research purpose only. The construction inputs of the case project were contextualized and verified by the group interview with relevant project stakeholders. The first group was related to internal construction inputs which can be controllable by managerial means of project stakeholders, they are manpower $\left(x_{1}\right)$, material $\left(x_{2}\right)$, equipment $\left(x_{3}\right)$ and site management $\left(x_{4}\right)$. The second group concerned external aspects which was under influence of external political and business environment, i.e., regulatory compliance $\left(x_{5}\right)$.

More specifically, the manpower input includes the cost of on-site labour and the expense associated with on-site training. The material input consists with the expense on direct and indirect construction materials as well as the material storage cost. The equipment input for the case project includes the rental and O\&M cost of the working equipment as well as the rental and storage cost for idle equipment. The input for site management in this project includes salary for the construction management team, external consultants' fee and other facility utilisation expense. The regulatory compliance input includes the expense on the health and safety insurance for labour as well as the cost environment protection, which includes noise barriers, water treatment system, etc. The value of construction output is the actual value of the work performed by the contractor from the perspective of client. 
MOC SUMMIT / MAY 2019

\section{Site efficiency estimation}

The optimized values of the parameters (Table 1) is presented below .

Table 1. The estimated values of the parameters

\begin{tabular}{cccccccc}
\hline$\gamma$ & $\rho$ & $v$ & $\alpha_{1}$ & $\alpha_{2}$ & $\alpha_{3}$ & $\alpha_{4}$ & $\alpha_{5}$ \\
\hline 2.0404 & 1.1306 & 1.1525 & 0.2579 & 0.2391 & 0.2359 & 0.1286 & 0.1385 \\
\hline
\end{tabular}

\section{Scenario analysis for evaluating SEESs}

Re-estimating the value of construction output at each observation period based on the baseline model, the controlled models I \&II\&III, the findings suggest that the value of construction output is improved by increasing the equipment and material investment along with decreasing labor investment (Figure 2). During the group interview, the chief engineer from contractor side addressed that this project largely relied on hand tools and manually controlled devices. He cited that there was only one tower crane on-site for moving heavy construction materials. However, other materials were moved manually through construction trolleys or wheelbarrows and lifted by material handling lifts. On the one hand, longer transportation time may increase waiting time for installation and thus impede site efficiency. On the other hand, hand tools and manually controlled devices required more labor to operate, in turn, increased pressure on labor investment. The findings call for an emphasis on increasing investment in construction equipment and machinery.

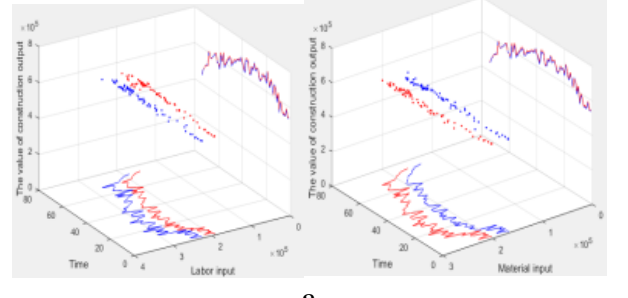

a

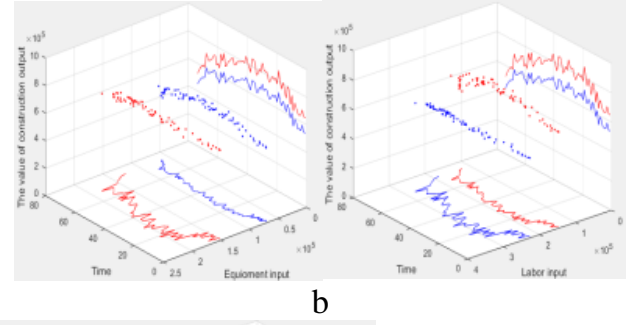

b
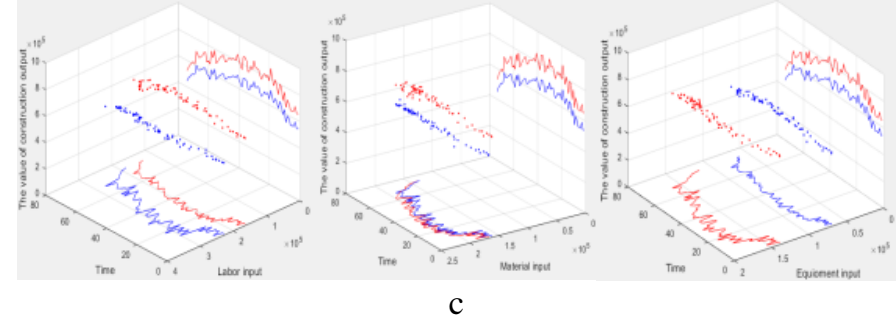

Figure 2. The value of labour, material and equipment inputs under the current run (blue) and the optimal scenario (red) for adopting: a) modularization; b) mechanization; and c) the both.

Analyzing the optimal scenarios of the controlled models I \&II\& III, simulation results suggest that the ratios of material-to-labor and equipment-to-labor are increased (Figure 3). More specifically, the results indicate that technology progress in construction materials could support the increase of the material-to-labor ratio of the construction project due to their abilities in substituting of material for labor. This is in line with the literature that labor-saving materials contribute to productivity enhancement (Goodrum et al. 2009) by transferring labor from on-site to off-site (Zhi et al. 2003). The findings indicate the positive tendency of modularization on site efficiency, thereby indicating that technologies in construction materials are beneficial for site efficiency enhancement by technological diffusion from the manufacturing to the construction through materials. A higher degree of equipment-to-labor ratio implies a higher degree of mechanization (Goodrum and Haas 2004). The simulation results of multiple scenarios suggest a 
higher degree of mechanization is more likely to result in site efficiency enhancement by substituting of equipment for labor.

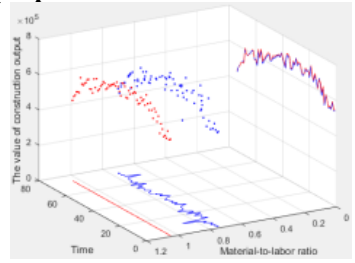

$\mathrm{a}$

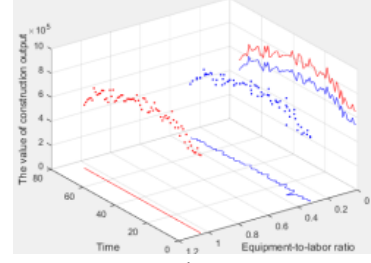

b

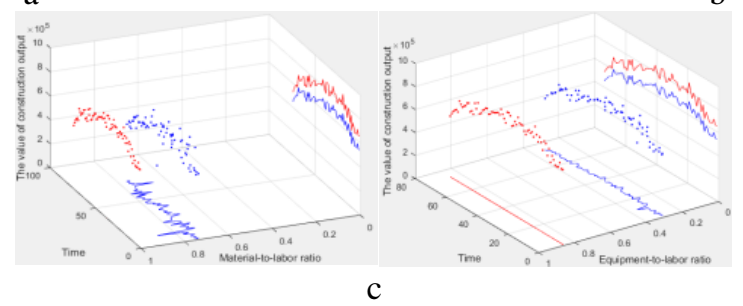

Figure 3. The material-to-labor ratio and equipment-to-labor ratio under the current run (blue) and the optimal scenario (red) for adopting: a) modularization; b) mechanization; and c) the both

Let the value of the constructed facility by the sum of the value of construction output at each observation period. Figure 4 shows that the value of the constructed facility increases as the increase of the investment of labor, material and equipment at the inception phase. While later on, the value of the constructed facility decreases as the increase of the three inputs. The findings suggest that simply increasing investment for a single construction input within a short period would help to enhance site efficiency (i.e., the value of the constructed facility is increased with the same inputs). However, the value of the constructed facility would decrease dramatically, if the combined effects of the inputs are not considered in a long-term perspective. This is in line with the literature which strategies for productivity enhancement should be systematically addressed and implemented (Pan et al. 2019).

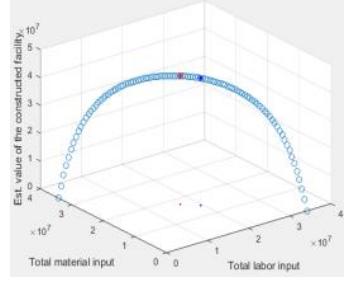

a

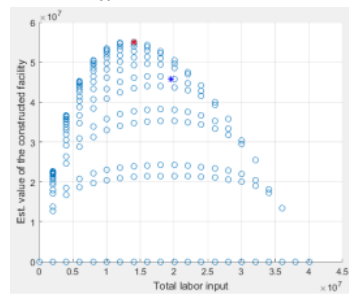

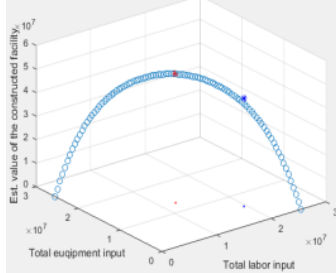

b

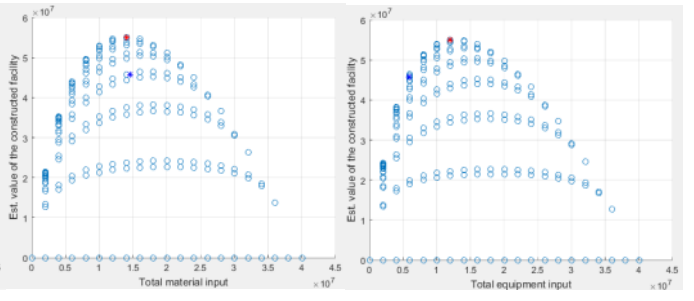

$\mathrm{c}$

Figure 4. The estimated value of the constructed facility under scenario adopting: a) modularization; b) mechanization; and c) the both

By site efficiency enhancement principle, i.e., "achieve more with less" (Mbachu and Seadon 2013; Mandal and Vong 2016), the models with a higher value than the baseline model are regarded as the site efficiency has been enhanced. To test the research hypotheses, the value of the constructed facility is re-estimated for the optimal scenarios of the three controlled models 
(Table 2). The results support all three hypotheses and suggest that the site efficiency of the case project can be enhanced by adopting modularization and mechanization. Specifically, the case project is beneficial to both technologies when they are within the relationship of symbiosis.

Table 2. The estimated values of the constructed facility under the four models

\begin{tabular}{cccc}
\hline Baseline model & Controlled model I & Controlled model II & Controlled model III \\
\hline 45.77 million RMB & 46.16 million RMB & 54.73 million RMB & 55.06 million RMB \\
\hline
\end{tabular}

In summary, the findings of the multiple scenarios contribute to the body of knowledge which the benefits of modularization and mechanization exist at the project level. In this respect, the results provide necessary quantitative evidence to support technological innovation in construction through modularization and mechanization for enhancing site efficiency of a construction project. Thus, the findings encourage the adoption of innovative construction materials and equipment in construction projects. The findings echo with literature concerning construction productivity enhancement strategies (Pan et al. 2019; Yang et al. 2018) and the group interview. The group interview highlighted the importance of material and equipment technologies during construction process by the deputy project manager and a representative of one material supplier.

\section{CONCLUSIONS}

This paper has developed a CES function-based site efficiency model that enables to combine various inputs for measuring site efficiency. To illustrate the applicability of the proposed methodology, the model was substantiated in a real-life building construction project. The case vividly showed that the benefits of adopting modularization and mechanization exist at the project level. The simulation results of multiple scenarios provide quantitative evidence to encourage innovation in construction materials and equipment and offer significant implications for stakeholders in the construction industry to improve their productivity in a fierce competition of the construction sector. Future research can conduct more empirical analysis of the symbiotic scenarios of modularization and mechanization in improving construction site efficiency.

\section{REFERENCE}

Abdel-Razek, R. H., Abd Elshakour M, H., andAbdel-Hamid, M. (2007).'Labor productivity: Benchmarking and variability in Egyptian projects'. International Journal of Project Management, 25, 189-197.

Abdel-Wahab, M., andVogl, B. (2011).'Trends of productivity growth in the construction industry across Europe, US and Japan'. Construction Management and Economics, 29(6), 635-644.

Borg, L., andSong, H.-S. (2015). 'Quality Change and Implications for Productivity Development: Housing Construction in Sweden 1990-2010'. Journal of Construction Engineering and Management, 141(1), 05014014.

Coelli, T. J., Rao, D. S. P., O’Donnell, C. J., andBattes, G. E. (2005).An introduction to efficiency and productivity analysis. Biometrics.

Ellis, R. D., andLee, S. (2006).'Measuring Project Level Productivity on Transportation Projects'. Journal of Construction Engineering and Management, 132(March), 314-321.

Goodrum, P. M., andHaas, C. T. (2004). 'Long-Term Impact of Equipment Technology on Labor Productivity in the U. S . Construction Industry at the Activity Level'. Journal of Construction Engineering and Management, 130(1), 124-133.

Goodrum, P. M., Zhai, D., andYasin, M. F. (2009).'Relationship between Changes in Material 
Technology and Construction Productivity'. Journal of Construction Engineering and Management, 135(4), 278-287.

Henningsen, A., andHenningsen, G. eraldine. (2011).'Econometric Estimation of the "Constant Elasticity of Substitution” Function in R: Package micEconCES'.

Jääskeläinen, A. (2010).Productivity Measurement and Management in Large Public Service Organizations. Tampere, Finland.

Javed, A. A., Pan, W., Chen, L., andZhan, W. (2018). 'A Systemic Exploration of Drivers for and Constraints on Construction Productivity Enhancement'. Built Environment Project and Asset Management, 8(3), 239-252.

Liao, P.-C., Thomas, S. R., O’Brien, W. J., Dai, J., Mulva, S. P., andKim, I. (2012).'Benchmarking Project Level Engineering Productivity'. Journal of Civil Engineering and Management, 18(2), 235-244.

Linna, P., Pekkola, S., Ukko, J., andMelkas, H. (2010). 'Defining and measuring productivity in the public sector: managerial perceptions'. International Journal of Public Sector Management, 23(5), 479-499.

Mandal, P., andVong, J. (2016).Smart technologies for smart nations: perspectives from the Asia-Pacific Region.

Mbachu, J., andSeadon, J. (2013).Productivity Improvement in Building Life Cycle. Development Process, Role-Players and Efficiency Improvement.

Mirahadi, F., andZayed, T. (2016). 'Simulation-based construction productivity forecast using Neural-Network-Driven Fuzzy Reasoning'. Automation in Construction, 65, 102-115.

Pan, W., Chen, L., andZhan, W. (2019).'PESTEL analysis of construction productivity enhancement strategies: A case study of three economies'. Journal of Management in Engineering, 35(1), 05018013.

Park, H.-S. (2006). 'Conceptual framework of construction productivity estimation'. KSCE Journal of Civil Engineering, 10(5), 311-317.

Pritchard, R. D. (1995).Productivity measurement and improvement: Organizational case studies. Praeger Publishers, Westport, CT.

Salter, W. (1966).Productivity and technical change. Cambridge Univer- sity Press, New York.

Sveikauskas, L., Rowe, S., Mildenberger, J., Price, J., andYoung, A. (2016).'Productivity Growth in Construction'. Journal of Construction Engineering and Management, 142(41), 04016045.

Thomas, B. H. R., Maloney, W. F., Smith, G. R., Handa, V. K., andSanders, S. R. (1990). 'Modeling Construction Labor Productivity'. Journal of Construction Engineering and Management, 116(4), 705-726.

Vogl, B., andAbdel-Wahab, M. (2015). 'Measuring the Construction Industry's Productivity Performance: Critique of International Productivity Comparisons at Industry Level'. Journal of Construction Engineering and Management, 141(4), 04014085.

Yang, Y., Pan, M., andPan, W. (2018). 'Co-evolution of innovative building technologies through interaction: The case of modular integrated construction and robotics'. CIOB (HK) Outstanding Paper Awards.

Yin, R. K. (2014).Case Study Research Design and Methods. SAGE Publications, Inc.

Zhan, W., andPan, W. (2018). 'A Theoretical Framework for the Systematic Construction Project Productivity Measurement: Reconceptualisation and Boundary Extension’. CRC 2018.

Zhi, M., Hua, G. B., Wang, S. Q., andOfori, G. (2003).'Total factor productivity growth accounting in the construction industry of Singapore'. Construction Management and Economics, 21(7), 707-718. 